\title{
Embolization of Intracranial Arteriovenous Malformations Using Onyx in 53 Patients
}

\author{
Ahmad Aoude, ${ }^{1,2}$ Hossein Ghanaati, ${ }^{1}$ Morteza Faghih Jouibari, ${ }^{3,}{ }^{*}$ Madjid Shakiba, ${ }^{1}$ Mehdi Khaleghi, ${ }^{3}$ \\ and Abbas Nowrouzi ${ }^{4}$ \\ ${ }^{1}$ Advanced Diagnostic and Interventional Radiology Research Center, Tehran University of Medical Sciences, Tehran, Iran \\ ${ }^{2}$ International Campus, Tehran University of Medical Sciences, Tehran, Iran \\ ${ }^{3}$ Department of Neurosurgery, Tehran University of Medical Sciences, Tehran, Iran \\ ${ }^{4}$ Brain and Spinal Injury Research Center, Tehran University of Medical Sciences, Tehran, Iran \\ "Corresponding author: Morteza Faghih Jouibari, Department of Neurosurgery, Tehran University of Medical Sciences, Tehran, Iran. Tel: +98-2184902272, Fax: +98-2188220040, \\ E-mail: mortezafaghihj@yahoo.com
}

Received 2016 March 09; Revised 2016 July 03; Accepted 2016 September 13.

\begin{abstract}
Background: Endovascular embolization is one of the main modalities in the treatment of brain arteriovenous malformations (AVMs). Onyx (ethylene-vinyl alcohol copolymer) is a new embolic agent with some advantages of slow injection and better control of penetration.

Objectives: To report our experience in the embolization of brain AVMs with Onyx.

Patients and Methods: From August 2012 to October 2014, 53 consecutive patients harboring brain AVM were treated with Onyx as the sole embolic agent during 85 procedures. There were 27 males and 26 females with a mean age of 27.2 years (range, 8 - 65 years). Results: The presenting symptom was headache in 25 (47\%), neurological deficit in 18 (35\%), and seizure in ten (18\%) patients. According to the Spetzler-Martin grading scale, three of the AVMs were ranked as grades I, 11 as grade II, 22 as grade III, 14 as grade IV, and three as grade V. An average of 1.8 feeding pedicles were embolized in each case, whereas a mean of 2.23-mL Onyx was used per patient. Initial complete obliteration at the end of all embolization procedures was achieved in 11 patients (20.08\%). The rate of complete embolization at 6-month follow-up was 15\%. After completion of embolization, the neurologic status was unchanged or improved in $46(87 \%)$ patients. We observed treatment-related neurologic deficit in seven (13\%) patients, of whom five were permanent (10\%). There was no procedure-related death.

Conclusion: Our experience with Onyx used for embolizing AVMs was satisfactory. Controlled injections that protect the draining veins make the therapy safe even in complex AVMs.
\end{abstract}

Keywords: Intracranial Arteriovenous Malformations, Endovascular Procedures, Ethylene Vinyl Alcohol Copolymer

\section{Background}

Brain arteriovenous malformations (AVMs) are complex vascular lesions in which an abnormal shunting of blood flow occurs from the arterial to the venous tree without an intervening capillary bed. Brain AVMs are relatively uncommon with a prevalence of less than $1 \%$ and an incidence between 0.01 and $0.001 \%$ (1-3). Patients with cerebral AVM may present with intracranial hemorrhage, seizure, headache, hydrocephalus, and focal or progressive neurological deficits. Major hemorrhage is the most serious complication of cerebral AVMs and it is the reason for presentation in more than $50 \%$ of symptomatic patients. Treatment of cerebral AVM comprises the following interventions, alone or in combination: surgery, stereotactic radiosurgery, and embolization. Embolization is mainly used to reduce the size of large AVMs, to enhance the safety of surgery, or to make the AVM amenable to radiosurgery, but in low-grade AVMs, embolization alone may be cura- tive and safe alternative to neurosurgical or radiosurgical strategies. The endovascular approach to AVM using different embolizing agents is a well-established treatment strategy. Onyx (ethylene-vinyl alcohol copolymer) is a lavalike, non-adhesive embolic agent and has several advantages over acrylic glue. It is approved by the food and drug administration for the management of cerebral AVM. It permits theoretically slower filling, better penetration, and obliteration of the nidus, providing a solid nidus cast due to its longer polymerization time and lack of adherence.

\section{Objectives}

The goal of this study was to assess the outcome and complications of endovascular occlusion of intracranial AVMs and report our experience using Onyx. 


\section{Patients and Methods}

\subsection{Patients}

Fifty three patients harboring intracranial AVM were referred to the advanced diagnostic and interventional radiology research centre (ADIR). They underwent at least one session of Onyx embolization between August 2012 and October 2014. There were 27 males and 26 females with a mean age of 27.2 years (range, 8 - 65 years). Indications for AVM embolization were: 1 , AVMs with a small nidus that complete occlusion seemed feasible; 2 , Volume reduction as an adjunctive therapy to surgery and focused irradiation; 3, Palliative occlusion of AVM to reduce risk of hemorrhage. Informed consent was obtained from all patients. All the patients were evaluated by four-vessel angiography (Artis zee biplane system - Siemens Healthcare) to determine the shape, size, feeders, and location of the AVM and to decide about the therapeutic protocol.

\subsection{Injection Procedure}

All AVM embolization procedures were performed under general anesthesia or deep sedation, and with systemic heparinization (5000 units in bolus when the guiding catheter is in place). A $6 \mathrm{~F}$ sheath was placed in one of the femoral arteries and a $6 \mathrm{~F}$ guiding catheter was then inserted in either an internal carotid or a dominant vertebral artery that gave the best supply to the AVM. The tip of the microcatheter was navigated as close as possible to the nidus meaning that the feeding arterial pedicle was navigated distally up to the nidal network. Onyx was slowly and progressively injected into the nidus under continuous visual control using biplane subtracted fluoroscopy. Every effort was made to occlude the arterial compartment of the AVM first to avoid bleeding complications associated with early occlusion of venous drainage and injection was interrupted whenever a main venous outlet was reached. Draining veins could be completely occluded only when the nidus was completely filled with Onyx. As soon as reflux was observed along the microcatheter, the injection was stopped for 5 minutes and then resumed. When reflux occurred repeatedly, embolization was continued via another arterial feeder. Whenever increased resistance of the injection was encountered, to avoid rupture of the microcatheter or vessels, further application of Onyx was discontinued. We did not use detachable microcatheters. Finally, after aspirating with the Onyx syringe, the microcatheter was removed by slowly increasing and then decreasing the tension on the tip until the microcatheter was released.

\subsection{Post-Procedural Assessment}

Post-embolization angiography was performed for the evaluation of the AVM size, feeder occlusion, and blood flow of other arteries. AVM-nidus size and occlusion percentage according to pre-embolization angiogram were recorded. All the patients underwent control brain computed tomography (CT) after the procedure. Neurological examination was performed by a neurosurgeon before and after the procedure. Approximately six months after the last embolization session, neurologic examination and digital subtraction angiography were repeated, and AVM size was evaluated (Figure 1). Following every embolization procedure, patients returned to the neuroradiology ICU ward and were normally discharged 24 hours later.

\subsection{Statistical Analysis}

We used SPSS ver 18 (SPSS Inc. Released 2009. PASW Statistics for Windows, Version 18.0. Chicago: SPSS Inc.) for statistical analysis. Continuous variables were presented by mean (range). Ordinal and categorical data were presented by number and percent.

\section{Results}

Fifty three patients underwent intracranial AVM embolization by Onyx as the sole embolic agent. The presenting symptom was headache in 25 (47\%), neurological deficit in 18 (35\%), and seizure in ten (18\%) patients. Preprocedural brain CT showed hemorrhage in 16 (30\%) patients, of whom nine had neurological deficit and seven had headache as the presenting symptom. According to the Spetzler-Martin (SM) grading scale (4), three of the AVMs were ranked as grade I, 11 as grade II, 22 as grade III, 14 as grade IV, and three as grade V. Nidus size was lower than $3 \mathrm{~cm}$ in 12 (22.6\%), $3-6 \mathrm{~cm}$ in 31 (58.5\%) and more than $6 \mathrm{~cm}$ in ten (18.9\%) patients. Totally, 20 AVMs (37.7\%) were in eloquent areas and regarding venous pattern, 36 patients had deep venous pattern (67.9\%) and the others had superficial venous pattern (17 patients, 32.1\%). There was aneurysm in arterial feeders of six (11\%) patients, of whom four showed hemorrhage in imaging.

All patients had one AVM. The most common location for AVMs was the occipital lobe in 12 patients. Five patients had infratentorial AVMs. They all presented with neurological deficit (three gait ataxia, one hemiparesis, and one diplopia). Other distributions have been mentioned in Table 1.

A total of 85 embolization procedures were performed with a mean of 1.7 per patient. Embolization session was 1 in 31 patients (58.5\%), 2 in 15 patients (28.3\%), 3 in 3 patients (5.7\%), and 4 and 5 each one in 2 patients (3.8\%). An average of 1.8 feeding pedicles were embolized in each case, whereas a mean of 2.23-mL Onyx was used per patient. 

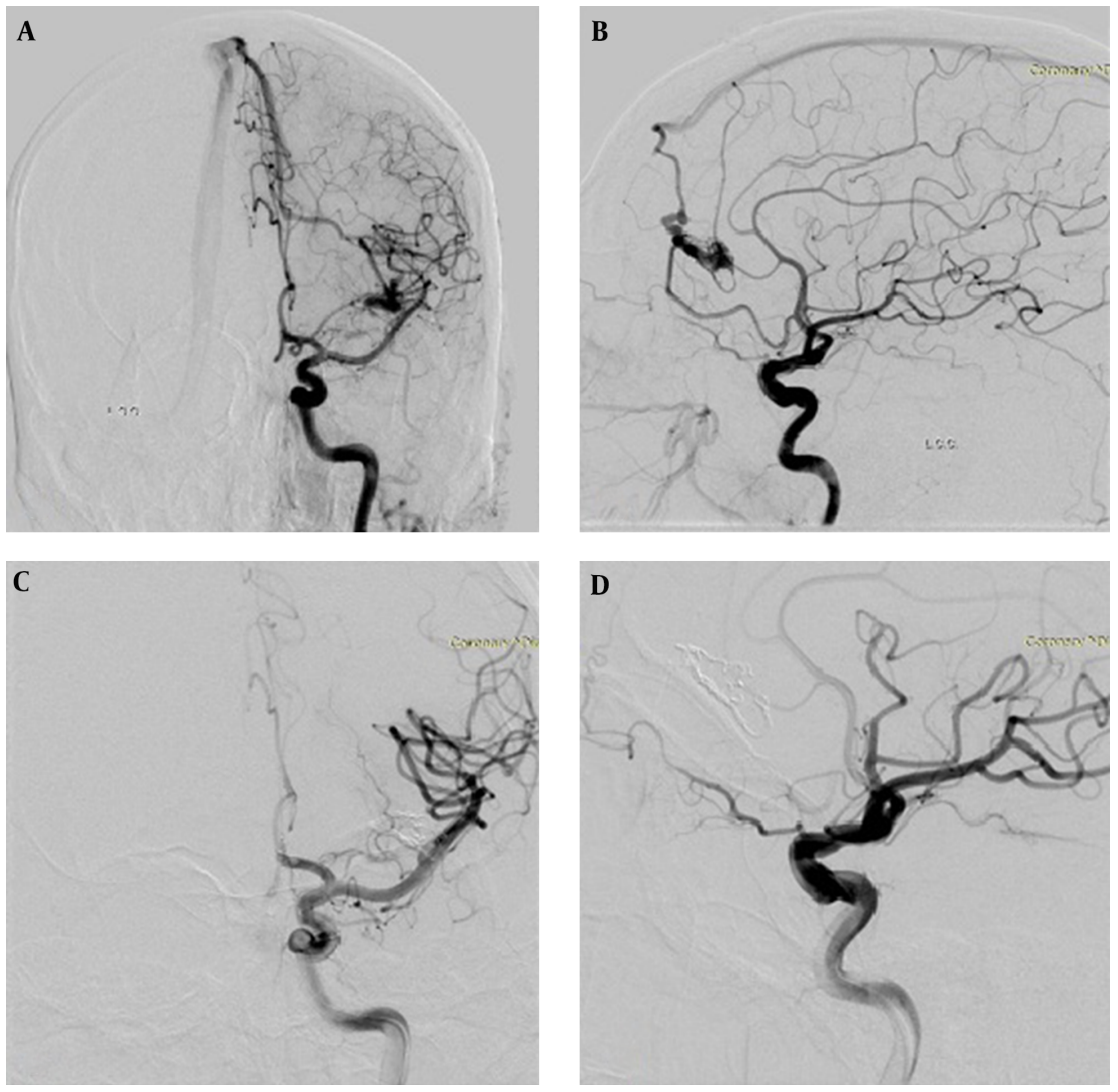

Figure 1. A 24-year-old male patient with a Spetzler-Martin (SM) grade I arteriovenous malformation (AVM) in the left frontal lobe. A and B, Anteroposterior and lateral carotid angiogram shows nidus with two arterial feeders from the left anterior cerebral artery and draining to the superior sagittal sinus. C and D, Control carotid angiogram at 6 months after embolization demonstrates complete AVM occlusion.

Initial complete obliteration at the end of all embolization procedures was achieved in 11 patients (20.08\%). According to the SM scale, 2 AVMs were grade I, 5 AVMs were grade II and 4 AVMs were grade III malformations. An average of $60 \%$ (range, $20 \%-100 \%$ ) volume reduction was achieved at the end of the endovascular procedures. Among patients with partially obliterated AVM, 4 patients underwent surgical resection and 12 patients were offered radiosurgery.

After a mean follow-up of 6 months, of the 11 initially completely embolized AVMs, 4 angiographic recurrences were evident. One of them underwent surgical excision, whereas 3 patients were scheduled for further embolization treatment. The rate of complete embolization at 6 month follow-up was $15 \%$.

After completion of embolization, the neurologic status was unchanged or improved in 46 (87\%) patients. We observed treatment-related neurologic deficit in 7 (13\%) (Table 2) patients (The deficits were temporary in 2 patients (3\%) but remained permanent in 5 patients $(10 \%))$. There was not procedure-related death. Eight patients developed symptomatic intracranial hemorrhage which 5 of them had related neurological deficit. Two patients developed neurological deficit without obvious bleeding.

\section{Discussion}

In current study the most common presenting symptom was headache that occurred in $22(42 \%)$ patients. It was accompanied by intracranial hemorrhage in 7 cases but in majority of patients, AVM caused headache without any hemorrhage. So, although hemorrhage is a common reason for initial presentation, a significant subset of patients may present with debilitating headaches that are not due to hemorrhage (5). Neurological deficit (30\%) and seizure (28\%) were other presenting symptoms.

Current treatment options for cerebral AVMs include microsurgical resection, endovascular embolization, and stereotactic radiosurgery. Endovascular intervention can 
Table 1. Distribution of AVM Location in the Brain

\begin{tabular}{lcc}
\hline Location & Frequency & Percent \\
\hline Frontal & 3 & 5.7 \\
Fronto-Temporal & 2 & 3.8 \\
\hline Temporal & 6 & 11.3 \\
\hline Parietal & 9 & 17.0 \\
\hline Occipital & 12 & 22.6 \\
\hline Fronto-Parietal & 1 & 1.9 \\
\hline Fronto-Temporo-Parietal & 1 & 1.9 \\
\hline Temporo-Parietal & 4 & 7.5 \\
\hline Parieto-Occipital & 8 & 15.1 \\
\hline Brain Stem & 1 & 1.9 \\
\hline Basal Ganglia & 2 & 3.8 \\
\hline Cerebellum & 4 & 7.5 \\
\hline
\end{tabular}

Abbreviarion: AVM, arteriovenous malformation.

be indicated for premicrosurgical embolization, preradiosurgical embolization, curative embolization, or palliative embolization. A wide variety of agents have been used to embolize AVMs. Onyx was first described by Yamashita et al. (6) and Terada et al. (7) in the 1990s. It is a polymerizing agent consisting of ethylene-vinyl alcohol dissolved in dimethyl sulfoxide and mixed with micronized tantalum powder for radiopaque visualization (8). The polymer solidifies slowly from outside to inside as it comes in contact with the blood, with limited influence by the AVM flow, allowing better control of penetration behavior and achieving more solid nidus cast compared with n-butyl cyanoacrylate ( $\mathrm{n}$-BCA). Embolization of AVM using Onyx has gained popularity for its non-adhesive yet cohesive nature, and its associated long injection time.

Recent studies that used Onyx as embolic agent for AVMs, have reported different complete obliteration rates. Gao et al reported 23 cases (26.1\%) of complete embolization among 88 patients (9), whereas Xu et al. described $16(18.6 \%)$ cases of total occlusions among 86 patients (10). Pierot et al reported a total occlusion in $8.3 \%$ among 50 AVMs embolized with Onyx (11). In a series of 23 AVMs embolized with Onyx by Jahan et al, the cure rate afte embolization was zero (12). In another series of 82 patients by Panagiotopoulos et al, 20 AVMs (24.4\%) were completely embolized with Onyx (13). Strauss et al in their series of 92 cases reported a $27 \%$ cure rate and concluded that complete obliteration rates were significantly higher in lesions with superficial big feeding arteries (14). According to the published experience up to now, complete obliteration rates of AVMs with Onyx range obviously above the re- ported average of 10\% of angiographic cure after embolization with n-BCA (15).

Our experience with use of Onyx for treatment of brain AVMs was satisfactory, with an average size reduction of $60 \%$, initial complete obliteration in $20.8 \%$ and complete occlusion at 6 month follow-up in 15\%. These results are comparable to other studies that used Onyx. Embolization performed during 1 or 2 sessions in most cases (46; 86\%) but it required more sessions in $7(13 \%)$ patients with SM grades IV-V AVMs.

The embolization-related morbidity and mortality of AVM can be substantial. Overall AVM embolization complication rates of approximately $5 \%$ to $15 \%$ have been reported $(16,17)$. Baharvahdat et al. reported an $11 \%$ complication rate after 846 intervention in 408 patients. New permanent disability and death related to hemorrhage after embolization were reported in $7.6 \%$ and $1.6 \%$ of patients, respectively (18). A meta-analysis by van Beijnum et al reported that complications leading to persistent neurological deficits or death occurred in $6.6 \%$ (range $0 \%-18 \%$ ) of patients after AVM embolization (19). In a series by Hartmann et al there were 233 patients who underwent AVM embolization with a goal of either endovascular or multimodality cure. They reported a $14 \%$ rate of embolizationrelated neurological deficits, a $2 \%$ rate of permanent disability, and a $1 \%$ rate of death (20). Taylor et al reported a $9 \%$ rate of permanent neurological deficits and a $2 \%$ rate of death due to embolization in their series of 201 patients undergoing premicrosurgical embolization (21).

Embolization procedures caused symptomatic hemorrhage (leading to neurological deficit, headache or nausea and vomiting) in eight of our patients, -five developed neurological deficits. Subtotal nidus occlusion followed by immediate or delayed thrombosis of the draining veins probably was the most important cause. Two patients developed neurological deficit without obvious bleeding and probably due to ischemic events. Most of new neurological deficits (6 of 7) developed in patients with AVM in eloquent areas. In two patients neurological deficit was transient. It improved at the 6-month follow up visit. Our complication rate of $13.2 \%$ is similar to other studies that used Onyx.

There are rare reports that the microcatheter was stuck in the nidus, but it occurred in none of our injections. Another concern with Onyx is that the prolonged time of injection can expose patients to a higher dose of radiation; however, in one study, it was in the lower part of the range in which nonstochastic effects may arise (22). We did not observe hair loss in any of our patients.

Our study was limited by the relatively small number of patients and lack of long-term follow-up.

In conclusion our experience with Onyx used for embolizing AVMs was satisfactory. Onyx is a nonadhesive 
Table 2. Treatment-Related Neurologic Deficits

\begin{tabular}{|c|c|c|c|c|c|}
\hline Patient Number & AVM Location & SM Grade & Complication & Permanent or Temporary & Hemorrhage \\
\hline 1 & Lt basal ganglia & V & Loss of consciousness and hemiparesis & Permanent & Yes \\
\hline 2 & Rt temporoparietal & IV & Hemianopia & Temporary & Yes \\
\hline 3 & cerebellum & IV & Limb ataxia & Permanent & No \\
\hline 4 & Rt frontoparietal & III & Lt hemiparesis & Permanent & Yes \\
\hline 5 & Rt frontal & III & Lt hemiparesis & Permanent & Yes \\
\hline 6 & Lt temporoparietal & V & Rt hemiparesis and dysphasia & Permanent & Yes \\
\hline 7 & Lt frontal & III & Rt lower limb weakness & Temporary & No \\
\hline
\end{tabular}

Abbreviations: AVM, arteriovenous malformation; Rt, right; Lt, left; SM, Spetzler- Martin.

agent with controllable endovascular behavior that allows more precise nidus penetration. Controlled injections that protect the draining veins make the therapy safe even in complex AVMs.

\section{Footnotes}

Authors' Contributions: Study concept and design, Hossein Ghanaati, Ahmad Aoude; acquisition of data, Ahmad Aoude; analysis and interpretation of data, Madjid Shakiba; drafting of the manuscript, Ahmad Aoude; critical revision of the manuscript for important intellectual content, Morteza Faghih Jouibari, Mehdi Khaleghi; statistical analysis, Madjid Shakiba; administrative, technical, and material support, Hossein Ghanaati, Ahmad Aoude; study supervision, Abbas Nowrouzi.

Financial Disclosure: There is no relevant financial relationships to disclose.

Funding/Support: There is no funding or support.

\section{References}

1. Crawford PM, West CR, Chadwick DW, Shaw MD. Arteriovenous malformations of the brain: natural history in unoperated patients. JNeurol Neurosurg Psychiatry. 1986;49(1):1-10. [PubMed:3958721].

2. Laakso A, Hernesniemi J. Arteriovenous malformations: epidemiology and clinical presentation. Neurosurg Clin NAm. 2012;23(1):1-6. doi: 10.1016/j.nec.2011.09.012. [PubMed: 22107853].

3. Ondra SL, Troupp H, George ED, Schwab K. The natural history of symptomatic arteriovenous malformations of the brain: a 24-year follow-up assessment. J Neurosurg. 1990;73(3):387-91. doi: 10.3171/jns.1990.73.3.0387. [PubMed: 2384776].

4. Spetzler RF, Martin NA. A proposed grading system for arteriovenous malformations. J Neurosurg. 1986;65(4):476-83. doi: 10.3171/jns.1986.65.4.0476. [PubMed: 3760956].

5. Hofmeister C, Stapf C, Hartmann A, Sciacca RR, Mansmann U, terBrugge K, et al. Demographic, morphological, and clinical characteristics of 1289 patients with brain arteriovenous malformation. Stroke. 2000;31(6):1307-10. [PubMed: 10835449].
6. Yamashita K, Taki W, Iwata H, Nakahara I, Nishi S, Sadato A, et al. Characteristics of ethylene vinyl alcohol copolymer (EVAL) mixtures. AJNR Am J Neuroradiol. 1994;15(6):1103-5. [PubMed: 8073979].

7. Terada T, Nakamura Y, Nakai K, Tsuura M, Nishiguchi T, Hayashi S, et al. Embolization of arteriovenous malformations with peripheral aneurysms using ethylene vinyl alcohol copolymer. Report of three cases. J Neurosurg. 1991;75(4):655-60. doi: 10.3171/jns.1991.75.4.0655. [PubMed: 1885987].

8. Alexander MJ, Tolbert ME. Targeting cerebral arteriovenous malformations for minimally invasive therapy. Neurosurgery. 2006;59(5 Suppl 3):S178-83. doi: 10.1227/01.NEU.0000238530.44912.01. [PubMed: 17053601] discussion S3-13.

9. Gao K, Yang XJ, Mu SQ, Li YX, Zhang YP, Lu M, et al. Embolization of brain arteriovenous malformations with ethylene vinyl alcohol copolymer: technical aspects. Chin Med J (Engl). 2009;122(16):1851-6. [PubMed: 19781359].

10. Xu F, Ni W, Liao Y, Gu Y, Xu B, Leng B, et al. Onyx embolization for the treatment of brain arteriovenous malformations. Acta Neurochir (Wien). 2011;153(4):869-78. doi: 10.1007/s00701-010-0848-6. [PubMed: 21046174].

11. Pierot L, Januel AC, Herbreteau D, Barreau X, Drouineau J, Berge J, et al. Endovascular treatment of brain arteriovenous malformations using Onyx: preliminary results of a prospective multicenter study. Intervent Neuroradiol. 2005;11(1 suppl):159-64.

12. Jahan R, Murayama Y, Gobin YP, Duckwiler GR, Vinters HV, Viñuela F. Embolization of arteriovenous malformations with Onyx: clinicopathological experience in 23 patients. Neurosurg. 2001;48(5):984-97.

13. Panagiotopoulos V, Gizewski E, Asgari S, Regel J, Forsting M, Wanke I. Embolization of intracranial arteriovenous malformations with ethylene-vinyl alcohol copolymer (Onyx). AJNR Am J Neuroradiol. 2009;30(1):99-106. doi: 10.3174/ajnr.A1314. [PubMed: 18842759].

14. Strauss I, Frolov V, Buchbut D, Gonen L, Maimon S. Critical appraisal of endovascular treatment of brain arteriovenous malformation using Onyx in a series of 92 consecutive patients. Acta Neurochir(Wien). 2013;155(4):611-7. doi: 10.1007/s00701-013-1633-0. [PubMed: 23430232].

15. Elsenousi A, Aletich VA, Alaraj A. Neurological outcomes and cure rates of embolization of brain arteriovenous malformations with n-butyl cyanoacrylate or Onyx: a meta-analysis. J Neurointerv Surg. 2016;8(3):265-72. doi: 10.1136/neurintsurg-2014-011427. [PubMed: 25540177].

16. Friedlander RM. Clinical practice. Arteriovenous malformations of the brain. N Engl J Med. 2007;356(26):2704-12. doi: 10.1056/NEJMcp067192. [PubMed: 17596605].

17. Arteriovenous malformations of the brain in adults. $N$ Engl J Med. 1999;340(23):1812-8. doi: 10.1056/NEJM199906103402307. [PubMed: $10362826]$. 
18. Baharvahdat H, Blanc R, Termechi R, Pistocchi S, Bartolini B, Redjem $\mathrm{H}$, et al. Hemorrhagic complications after endovascular treatment of cerebral arteriovenous malformations. AJNRAm JNeuroradiol. 2014;35(5):978-83. doi: 10.3174/ajnr.A3906. [PubMed: 24676002].

19. van Beijnum J, van der Worp HB, Buis DR, Al-Shahi Salman R, Kappelle LJ, Rinkel GJ, et al. Treatment of brain arteriovenous malformations: a systematic review and meta-analysis. JAMA. 2011;306(18):2011-9. doi: 10.1001/jama.2011.1632. [PubMed: 22068993].

20. Hartmann A, Pile-Spellman J, Stapf C, Sciacca RR, Faulstich A, Mohr JP, et al. Risk of endovascular treatment of brain arteriovenous malfor- mations. Stroke. 2002;33(7):1816-20. [PubMed: 12105359].

21. Taylor CL, Dutton K, Rappard G, Pride GL, Replogle R, Purdy PD, et al. Complications of preoperative embolization of cerebral arteriovenous malformations. J Neurosurg. 2004;100(5):810-2. doi: 10.3171/jns.2004.100.5.0810. [PubMed: 15137598].

22. Kemerink GJ, Frantzen MJ, Oei K, Sluzewski M, van Rooij WJ, Wilmink J, et al. Patient and occupational dose in neurointerventional procedures. Neuroradiology. 2002;44(6):522-8. doi: 10.1007/s00234-002 0780-4. [PubMed: 12070727]. 